\title{
CUSTO OPERACIONAL DO CURATIVO E CRITERIOS PARA SUA CLASSIFICAÇÃO
}

\author{
Maria José Schmidt *
}

\section{I - INTRODUÇÃO}

A técnica de curativo constitui um dos procedimentos básicos de execução rotineira na enfermagem. Entretanto, escapa à preocupação do executante avaliar o custo desse trabalho nos diversos aspectos relativos a material, mão-de-obra, medicamentos, instalações etc..

A necessidade de serem estabelecidos critérios para uma valorização mais justa, pautados em princípios científicos, foi uma das motivações para a realização do presente estudo.

Portanto, este trabalho é o resultado de experimentações, de pesquisa de preço e processos de classificação dos curativos nos diversos hospitais, ambulatórios e entidades outras de prestação de serviços médicos, de observação controlada da sua execução e, também, da experiência profissional. Não pode ter, é óbvio, a pretensão de apresentar um modelo que integre todas as variáveis que envolvem a problemática do custo operacional do curativo ou de sua classificação. É, todavia, uma tentativa de construir um padrão técnico elevado, dentro de um custo razoável.

\section{II - PESQUISA DE MERCADO}

1 - A pesquisa realizada durante o $2 .^{\circ}$ semestre de 1971 e início de 1972, em várias entidades médicas estatais e paraestatais, assim como em 20 hospitais e ambulatórios da Capital e da Grande São Paulo, evidenciou uma carência de critério científico para classificação e valorização dos curativos executados pelo pessoal de enfermagem. A grande maioria é efetuada por atendentes de enfer-

(*) Enfermeira do INPS - S.P. 
magem, sem treinamento adequado. Verificou-se que a classificação é arbitrária e subjetiva, baseada na experiência e conceituação individuais do executante. A nomenclatura de classificação geralmente utilizada é: curativo pequeno, médio e grande.

1.1 - Os preços médios encontrados nas épocas indicadas e já com a correção de $20 \%$ pela majoração do salário-mínimo ocorrido em maio de 1972 , foram os seguintes:

\section{$\operatorname{Cr} \$$}

1.11 - Curativo pequeno $\ldots$..

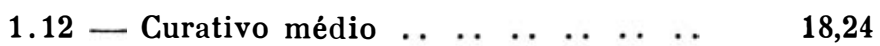

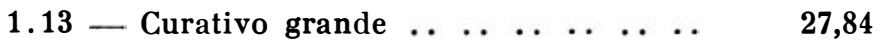

2 - Face suas características peculiares, aos curativos de queimaduras foi atribuída, em separado, a seguinte classificação: simples e especiais, conforme é feito em alguns hospitais pesquisados.

2.1 - Os preços médios encontrados foram os seguintes:

2.11 - Queimados simples ou não infectados: $\operatorname{Cr} \$ 36,00$ a $\operatorname{Cr} \$ .48,00$.

2.12 - Queimados especiais ou infectados: $\operatorname{Cr} \$ 48,00$ a $\mathrm{Cr} \$ 60,00$

Nota: Estes preços referem-se, apenas, aos curativos executados nos ambulatórios.

\section{III - CRITERIOS PARA CLASSIFICAÇÃO}

1 - A subdivisão da figura humana em regiões topográficas, tal como é utilizada em clínicas de queimados para cálculo da área lesada, foi o sistema aproveitado, alterando-se os percentuais a fim de melhor se ajustarem às características dos curativos e permitirem maior facilidade de classificação. Assim, estabeleceu-se:

1.1 - Curativos pequenos, quando a lesão atinge até $5 \%$ da área corpórea.

1.2 - Curativos médios, quando a lesão atinge de 5,1 a $20 \%$ da área corpórea.

1.3 - Curativos grandes, quando a lesão atinge acima de $20 \%$ da área corpórea. 
2 - Dentro da conceituação clássica na enfermagem, intitulam-se simples os curativos limpos e secos. Entretanto, para os fins deste trabalho, foram incluídos nessa denominação os cirúrgicos e os traumáticos superficiais não-infectados. Dentro dessa linha de conceituação, foram considerados especiais os curativos cirúrgicos sépticos e os traumáticos profundos, infectados ou não.

3 - Atendendo às peculiaridades das queimaduras, os curativos foram, também, subdivididos em simples e especiais na forma como se segue:

3.1 - Curativos simples: as queimaduras de $10^{\circ}$ e $2 .^{\circ}$ graus não infectadas.

3.2 - Curativos especiais: as queimaduras de $10^{\circ}$ e $2 .^{\circ}$ graus sépticos e as de $3 .^{\circ}$ grau infectadas ou não.

4 - A figura humana representada no Anexo I possibilita a mensuração da área corpórea comprometida pela lesão. Os percentuais fixados nas áreas delimitadas no desenho servem de base para o estabelecimento de valores, conforme a classificação em pequenos, médios ou grandes.

\section{1 - Exemplo:}

Diagnóstico - lesão cortocontusa do tórax e abdome.

Percentuais das áreas atingidas: $3+3=6 \%$

\section{IV - CUSTO OPERACIONAL}

Custo operacional é o valor global despendido na execução de uma técnica ou serviço. Neste trabalho, o custo operacional do curativo foi obtido mediante a apuração das despesas relativas ao material utilizado, à mão-de-obra, às instalações e à administração.

1 - A quantidade média do material usado em curativos resultou de experimentação técnica, pela mensuração quantitativa das diversas drogas utilizadas e através de uma observação controlada clurante quinze dias úteis, a fim de se fixarem a quantidade e a qualidade do material usado em diversos tipos de curativos, bem como o tempo gasto na sua realização.

1.1 - 0 Anexo.$^{\circ} 2$ apresenta a média do material utilizado e do tempo de execução. Evidentemente, pode haver oscilação para mais ou para menos ou ocorrer que, em determinados curativos, não sejam usados todos os medicamentos e materiais descritos no quadro em referência. 
2 - O Anexo n..$^{\circ}$ mostra o valor monetário do material, por unidade de aquisição (forma de apresentação) e por unidade ou fração utilizável. Os cálculos foram baseados em elementos da revista "BRASINDICE", de fevereiro de 1972, e de coleta de preços na Divisão de Material do INPS.

3 - 0 custo do material utilizado por curativo, foi obtido obedecendo-se a classificação do item III, (curativo pequeno, médio e grande; simples e especial; queimadura simples e especial) multiplicando-se o valor unitário encontrado no Anexo n. 3 pela correspondente quantidade de material usado de acordo com o Anexo n. ${ }^{\circ}$ 2. Manuseando-se simultaneamente os quadros dos Anexos n. ${ }^{\circ}$ 2 e 3, serão obtidos os resultados do Anexo n. 4 que apresentam a apuração global, por tipo de material utilizado no procedimento. Exemplo: para conhecer o custo em compressa de gase para um curativo pequeno especial, multiplica-se $\operatorname{Cr} \$ 0,03$ (valor unitário) por 15 (quantidade gasta) e assim obteremos $\operatorname{Cr} \$ 0,45$.

4 - Entretanto, há que considerar que o custo não é apenas de material de consumo mas também de outras despesas de difícil individualização e caracterização. Tradicionalmente, vem sendo acrescido um percentual de 25 a $30 \%$ como taxa de administração, na prestação de qualquer serviço. Sendo pacificamente aceito, esse percentual pode ser incluído também no curativo, a fim de dar cobertura a gastos de: depreciação do material permanente e instalações, preparo e esterilização do instrumental, limpeza e manutenção das salas de curativos, roupas, assim como a mão-de-obra, seja da equipe de enfermagem ou de limpeza.

O Anexo n. 5 demonstra, de modo global, o cálculo do custo operacional do curativo. O valor do item material corresponde ao total respectivo aferido no Anexo $\mathrm{n}^{\circ}$ 4, que somados aos $30 \%$ para despesas administrativas, consignarão o custo real. Desta forma ficou evidenciado o valor global dispendido na execução da técnica de curativo. Encontrado o custo, pode-se dizer que o que exceder será o lucro.

\section{V - VALORIZAÇÃO DO CURATIVO EM UNIDADES DE SERVIÇO - US}

A Unidade de Serviço - US - adotada pela Resolução, ainda vigente, $n .^{\circ}$ CD 1.657/62 do extinto DNPS, é uma medição já consagrada pelo uso comum nas entidades credenciadas pelo INPS, para prestação de assistência médica. Equivale a 1/100 (um centésimo) da média aritmética dos maiores salários-mínimos regionais do País. 
O vaior do serviço prestado é arbitrado em US. Para se saber o valor em cruzeiros, multiplica-se o valor de cada US atualizado, pelo número de US atribuído ao serviço. Exemplo:

Valor da US $=\operatorname{Cr} \$ 1,97$ (a partir de 01-03-72)

Curativo pequeno $=1$ US. Portanto, $1 \times \operatorname{Cr} \$ 1,97=\operatorname{Cr} \$ 1,97$.

\section{QUADRO DEMONSTRATIVO DOS VALORES ATRIBUfDOS AOS CURATIVOS}

\begin{tabular}{ccccc}
\hline \hline $\begin{array}{c}\text { Especificação } \\
\text { do } \\
\text { Curativo }\end{array}$ & $\begin{array}{c}\text { Superfície corpórea comprometida } \\
\text { Pequeno } \\
\text { até 5\% }\end{array}$ & $\begin{array}{c}\text { Médio de } \\
5,1 \text { a } 20 \%\end{array}$ & $\begin{array}{c}\text { Grande } \\
\text { acima de 20\% }\end{array}$ \\
\hline Simples . . . . . . . . & 1 US & $11 / 2$ US & 3 US \\
Especial . . . . . . . & 1 US & 2 US & 5 US \\
Queimado - simples . . . & 4 US & $71 / 2$ US & 13 US \\
Queimado - especial . . . & 5 US & 9 US & 16 US \\
\hline \hline
\end{tabular}

\section{VI - CONCLUSÕES}

O objetivo de melhorar o padrão de assistência integral ao paciente exige estudo de novos meios e condições diretas ou indiretas, de adaptações e reformulações dos sistemas e técnicas, de acordo com as necessidades, para a canalização racional dos recursos materiais e humanos.

O treinamento adequado, com vistas à redução de esforços ociosos; maior adaptação dos executantes às suas tarefas; tudo aliado ao of erecimento de melhores condições e facilidades no trabalho, constitui um dos meios para a consecução do objetivo colimado. A técnica deve propiciar melhor padrão de serviço, com maior economia de material, de tempo e de pessoal.

O Grupamento de Acidentes do Trabalho do INPS, como entidade recebedora de prestações de assistência médica, preocupa-se em pautar suas decisōes dentro de um critério mais justo e que possibilite um melhor padrão de atendimento. 


\section{A NEXO 1}

DIVISÃO TOPOGRÁFICA DA FIGURA HUMANA

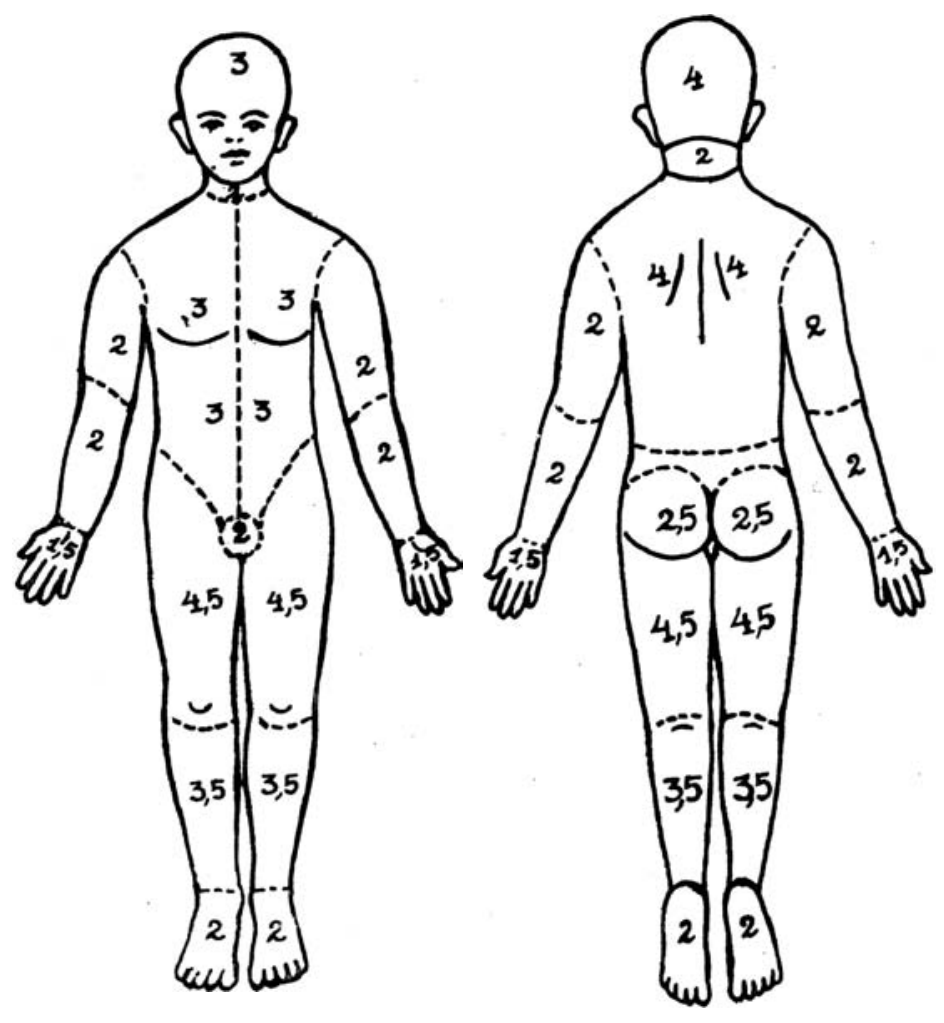




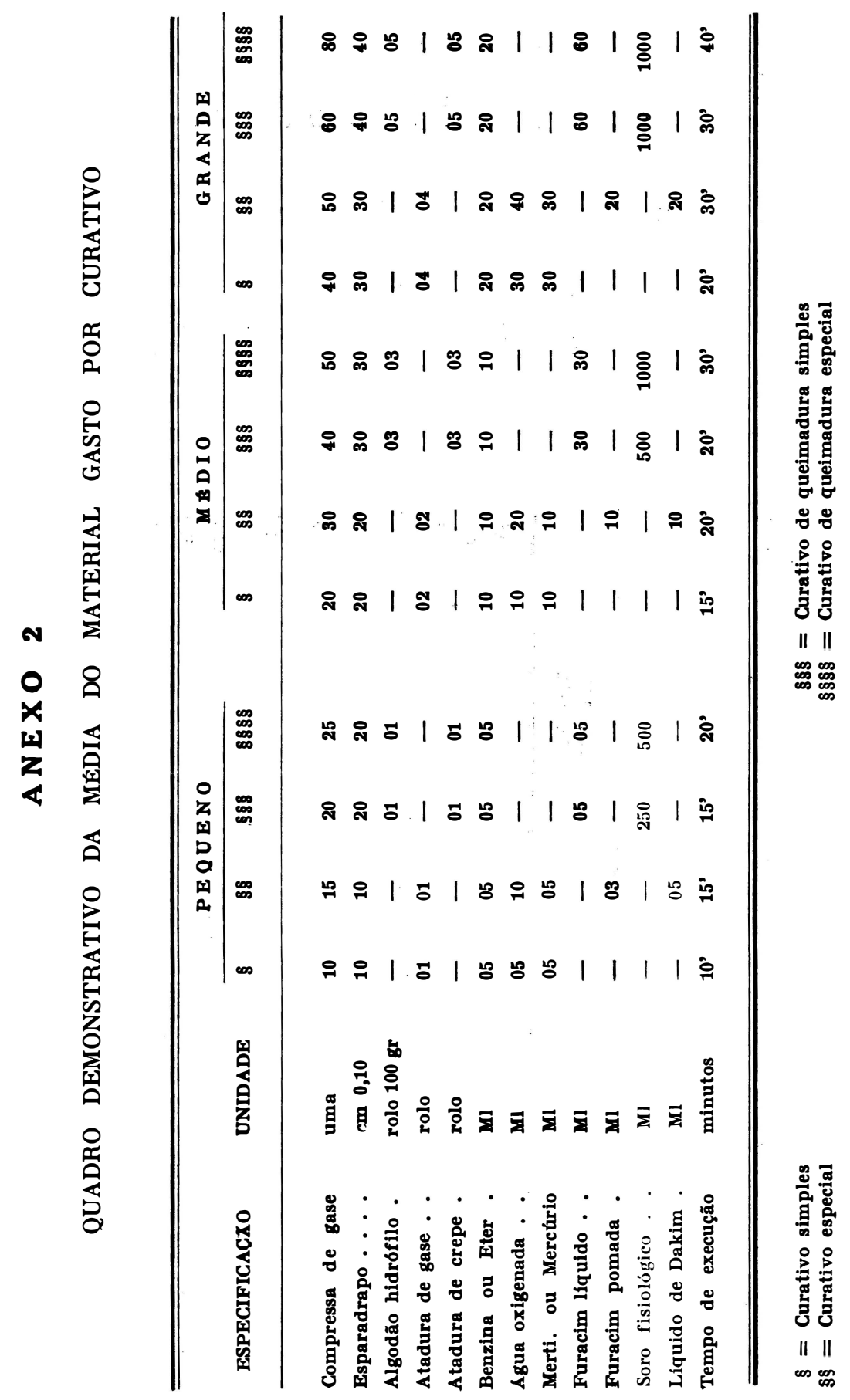




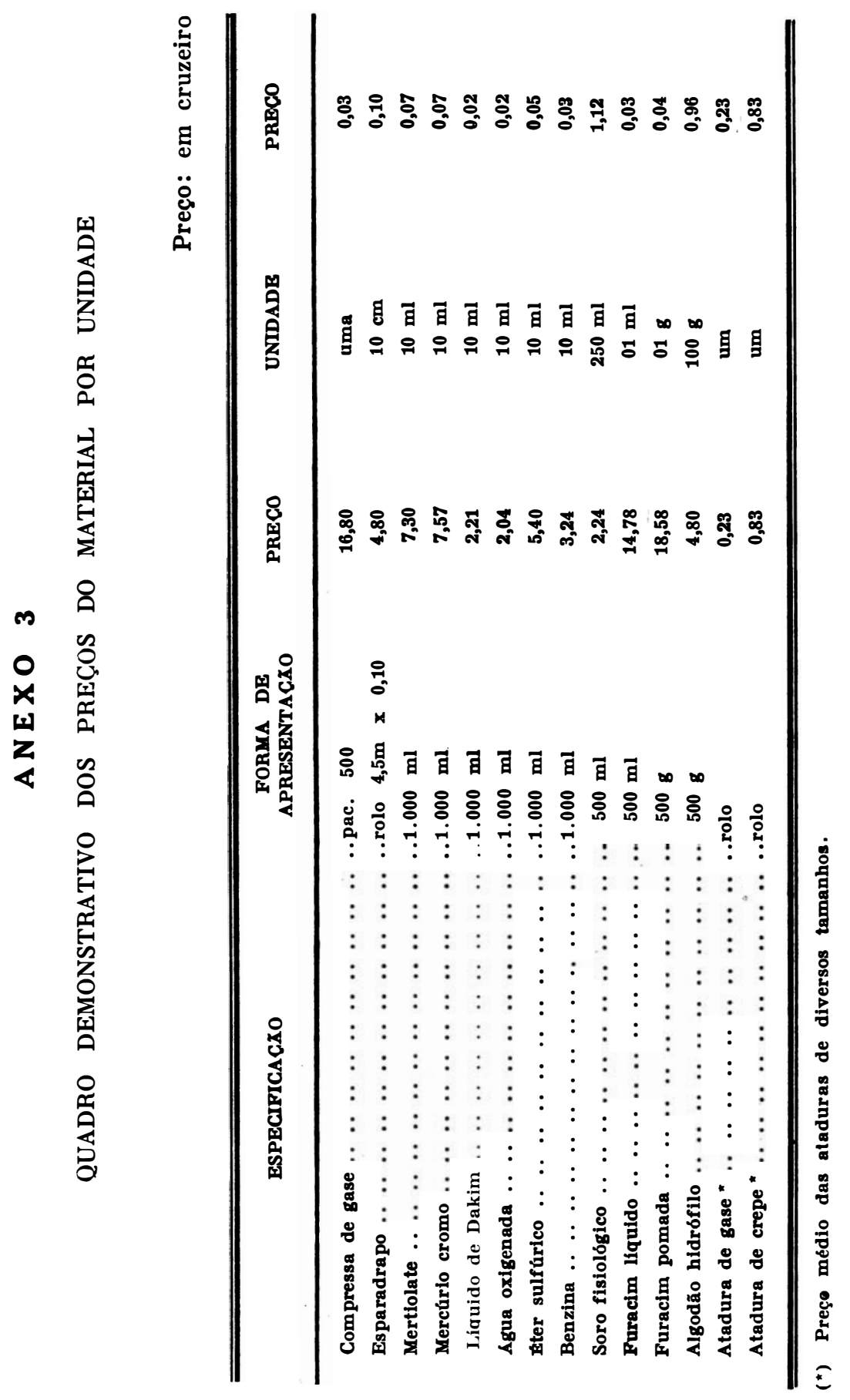




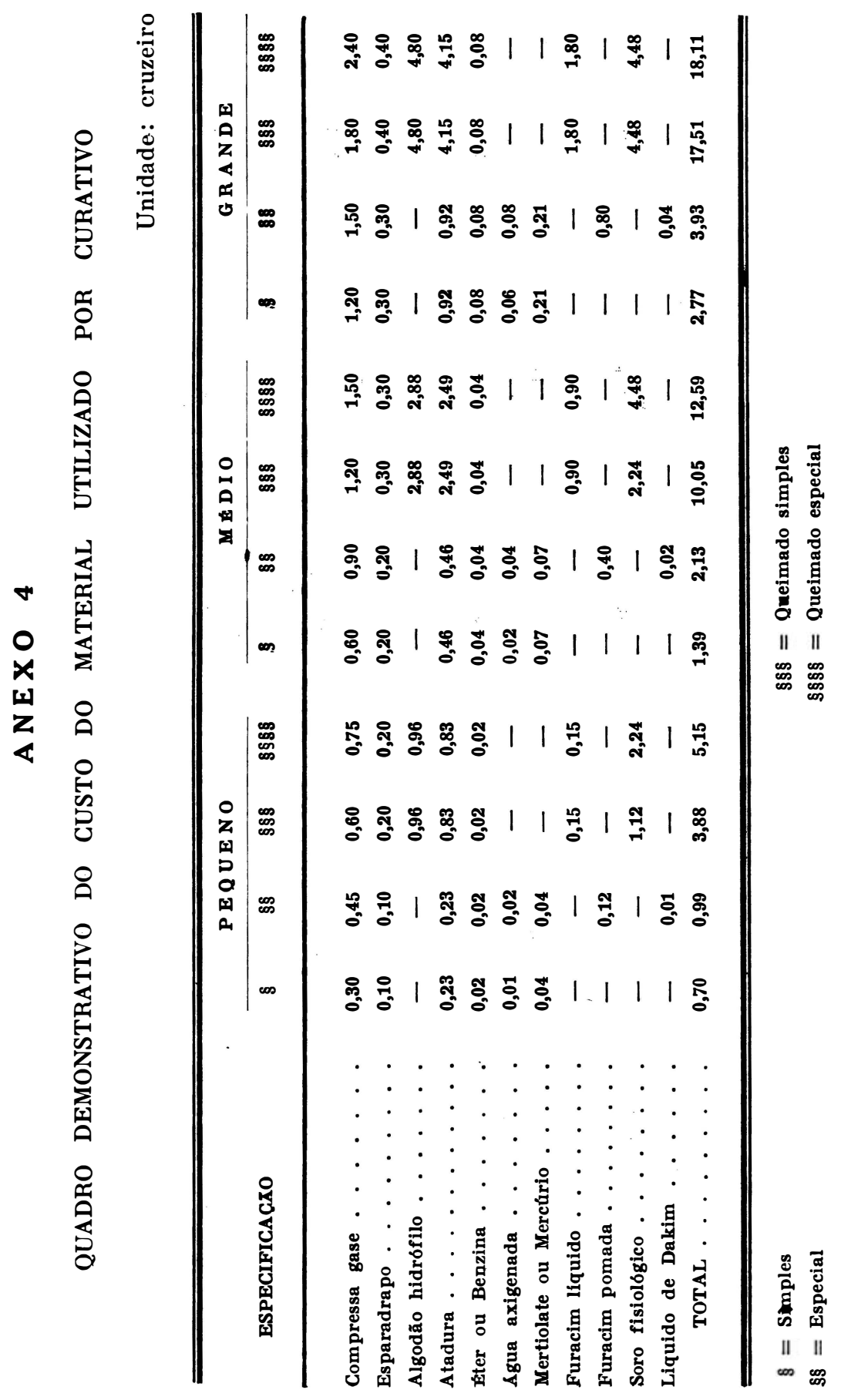




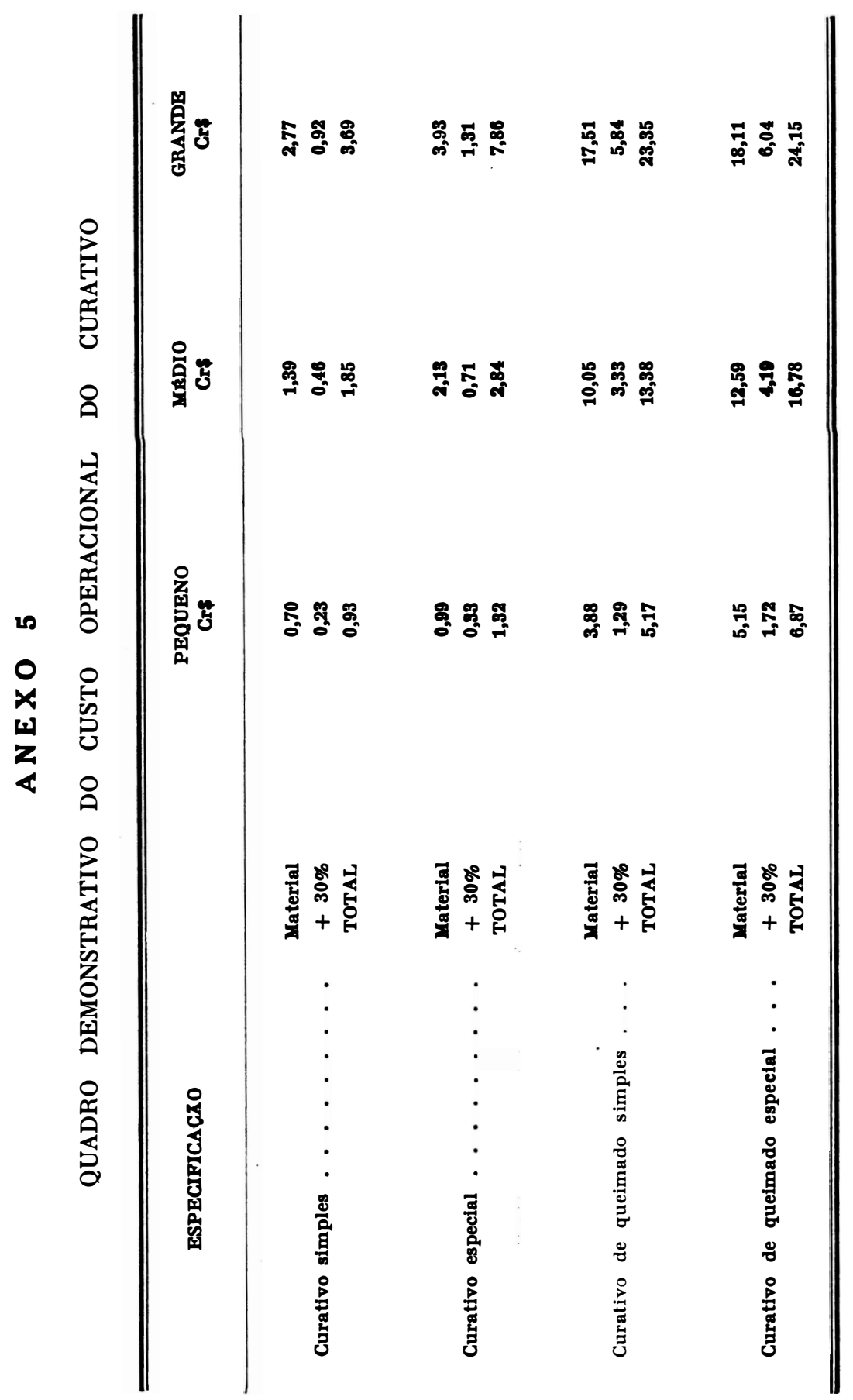

